REVIEW ARTICLE

AFRICAN JOURNAL OF CLINICAL AND EXPERIMENTAL MICROBIOLOGY

MAY 2013

AJCEM/21318

COPYRIGHT 2013

AFR. J. CLN. EXPER. MICROBIOL 14(2): 105-108 http:// dx.doi.org/10.4314/ajcem.v14i2.11

\title{
CAUSATIVE AGENTS OF KERATOMYCOSIS IN IBADAN: REVIEW OF LABORATORY REPORTS
}

\author{
Fayemiwo, S.A. ${ }^{1}$, Ogunleye, V.O. ${ }^{1}$ Ashaye A.O. ${ }^{2}$, Oladele, R ${ }^{1}$, Alli, A.J. ${ }^{1}$, and Bakare, R.A. ${ }^{1}$ \\ ${ }^{1}$ Departments of Medical Microbiology \& Parasitology and ${ }^{2}$ Ophthalmology, University College Hospital, Ibadan, Nigeria. \\ Correspondence: Dr. Fayemiwo, S.A., Department of Medical Microbiology \& Parasitology, College of Medicine, University of \\ Ibadan; University College Hospital, Ibadan. E-mail: dayteet@yahoo.com , safayemiwo.comui.edu.ng
}

\begin{abstract}
Introduction: Fungi are responsible for less than $2.0 \%$ of corneal infection around the globe. Trauma to the cornea is the leading cause of fungal keratitis especially with history of corneal trauma with vegetable or organic matter. Because of the dearth of data on the aetiological agents of Keratomycosis in this hospital, this study was aimed at finding the prevalence and fungal etiological agents responsible for this condition Ibadan, Nigeria. Methods: A retrospective review of the laboratory reports of corneal scrapings of patients that presented with signs and symptoms suggestive of Keratomycosis was carried out. The scrapings were subjected to wet preparation with $10.0 \% \mathrm{KOH}$, Gram staining and Giemsa staining to rule out inclusion bodies. The diagnosis of Keratomycosis was made on the basis of the recognizable and characteristic appearance of fungal hyphae and fruiting bodies under microscopy. The media with no obvious growth after 3-4 weeks of incubation were regarded as negative. Results: A total of 48 specimens from patients with suspected diagnosis of Keratomycosis were included in the analysis. The patients consisted of $42(87.3 \%)$ males and $6(12.5 \%)$ females. The ages at diagnosis ranged from 3 to 73 years with a mean of 36.46 years and a median of 35.5 years. The prevalence of Keratomycosis among this group of patients in this hospital was $8.4 \%$. Candida albicans and Fusarium spp were the fungal isolates in these patients as it occurred in $4.2 \%(2 / 48)$ of them respectively. Conclusions: Corneal scarring due to trauma or infections is a major cause of monocular blindness, especially in developing countries like Nigeria. Despite the low level of Keratomycosis in this study, high index of suspicion of possible diagnosis should be giving to patients with history of trauma, tissue devitalization with topical steroids and immunocompromised immunity.
\end{abstract}

Keywords: Keratomycosis, Corneal, Fusarium and Candida.

\section{INTRODUCTION}

According to the World Health Organization, corneal diseases are a major cause of vision loss and blindness, second only to cataract in overall importance (1). It is estimated that ocular trauma and corneal ulceration result in 1.5 to 2 million new cases of corneal blindness annually. ${ }^{1}$ Trauma is the most common precipitating factor in most of the cases (2). Trauma leads to destruction of the epithelium and Bowman's membrane, impairing barrier to infection. The underlying stroma becomes, excessively hydrated and possibly altered in such a way to constitute a more favorable site for fungus to grow (2). Keratomycosis caused by filamentous fungi is an occupational hazard of farmers and agricultural workers (3).
Keratomycosis is a major cause of visual disability in developing countries $(1,4)$. Fungi have replaced bacteria as the predominant cause of infectious keratitis in some developing countries like Nigeria (1). Fungal keratitis is a major blinding eye disease in Asia and other developing countries $(2,5)$. One report from South India found that $44 \%$ of all central corneal ulcers are caused by fungi (2). This high prevalence of fungal pathogens in South India is significantly greater than that found in similar studies in Nepal $(17 \%)$, Bangladesh (36\%), Ghana (37.6\%), and south Florida (35\%) (6-10).

It has also been postulated that the lower temperature of the cornea relative to the rest of the body may favor the growth of fungi (9). Many ophthalmologists also identified topical steroids as the principal risk factor in enhancing ocular fungal growth (11). Steroid use 
as initial therapy was reported in 1 to $30 \%$ of patients having microbial keratitis (11).

Keratomycosis can be caused by as many as 60 species of fungi. The predominant etiological agents vary in different geographical areas. However, Aspergillus spp. is the commonest isolate in India (12-

13). Most cases of mycotic keratitis are amenable to treatments if effective topical antifungal therapy is started early. The major hurdle to this lies in definitive laboratory diagnosis in clinically suspected case of oculomycosis. False negative diagnostic results may result in delay in institution of anti fungal therapy (2).

Because of the dearth of data on the prevalence of Keratomycosis in this hospital, this study was aimed at finding the prevalence and fungal etiological agents responsible for this condition.

\section{METHODS}

This study was carried out in the Department of Medical Microbiology, University College Hospital, Ibadan, Nigeria. It was a retrospective review of the laboratory reports of corneal scrapings of patients that presented with signs and symptoms suggestive of Keratomycosis. The materials for culture and microscopic examination were obtained from the lesion.

The scrapings were subjected to wet preparation with $10.0 \% \mathrm{KOH}$, Gram staining and Giemsa staining to rule out inclusion bodies. The diagnosis of Keratomycosis was made on the basis of the recognizable colonial morphology, characteristic appearance of fungal hyphae and fruiting bodies under microscopy.
The corneal scrapings were also cultured on the Sabouraud Dextrose agar at room temperature (27$30^{\circ} \mathrm{C}$ ). Fungal growth occurred within 48 hours to three weeks. Once fungal growth appeared on primary isolation medium, colonies were subcultured promptly to fresh medium for isolation and identification in pure cultures. These fungi were identified with the aid of recognizable colonial morphology, microscopical appearance and biochemical reactions. All fungal cultures plates were kept for at least 3 week after inoculation before being declared negative. The data collected were analyzed with the aid of SPSS version 12.0 computer software.

\section{RESULTS}

A total of 48 patients with suspected diagnosis of Keratomycosis were included in the analysis. The patients consisted of $42(87.3 \%)$ males and $6(12.5 \%)$ females. The ages at diagnosis ranged from 3 to 73 years (Mean - 36.5 years, median of 35.5 years and SD $=8.6)$.

The prevalence of positive culture results for Keratomycosis among this group of patients in this hospital was $8.4 \%$.

Candida albicans and Fusarium spp were the fungal isolates in these patients as it occurred in $4.2 \%(2 / 48)$ of each of them respectively.

There was no statistical significance associated between age of presentation and types of fungi isolated $(\mathrm{P}>0.05)$. Though, there was no statistical significance between sex and fungi isolated $(P>0.05)$, it was noted that all the fungi were commonly isolated from male gender in their thirties.

TABLE 1: DISTRIBUTION OF THE FUNGAL PATHOGENS.

\begin{tabular}{|l|l|l|}
\hline Fungal isolates & Frequency $(\mathrm{n}=48)$ & Percentage (\%) \\
\hline Fusarium spp & 2 & 4.2 \\
\hline Candida albicans & 2 & 4.2 \\
\hline
\end{tabular}

\section{DISCUSSION AND CONCLUSION}

Mycotic keratitis is an infection of the cornea by the fungus that causes ulceration and inflammation, usually following trauma or treatment for a bacterial infection with steroid and antibiotics. Fungal keratitis is responsible for a significant burden of blinding disease in the developing world (14). Despite the known potential for visual impairment and blindness 
associated with fungal keratitis, few research studies have evaluated the risk factors and etiological agents in Nigeria. Corneal scarring due to trauma or infections is a major cause of monocular blindness, especially in developing countries like Nigeria.

More than 70 genera of moulds and yeasts have been associated with Keratomycosis (15). Hyaline moulds like Aspergillus, Fusarium, Cephalosporium, Acremonium and Penicillium are more frequently isolated as causative agents than phaeoids (dematiaceous fungi) moulds like Alternaria, Curvularia, Bipolaris and Exserohilum species $(16,17)$.

In this study, Fusarium and Candida spp. are the most common causes of fungal keratitis. This was found to be consistent with other studies in developing countries $(10,18)$. In India, Aspergillus and Fusarium are the commonest cause of Mycotic keratitis (16).

Chang et al. (19) from Taiwan have reported that Fusarium species are common plant pathogens, particularly in corn crops or onion fields. Gopinathan et al. (20) from India also reported Candida as a rare fungal corneal pathogen $(0.7 \%)$. In a series of 24 patients also from Wills Eye Hospital, Philadelphia, Candida was identified in $45.8 \%$ of cases of fungal keratitis; this probably represents the only study reporting Candida as the commonest etiologic agent of fungal keratitis (21).

\section{REFERENCES}

1. Whitcher JP, Srinivasan M, Upadhyay MP: Corneal blindness: A global perspective. Bull World Health Organ 2001, 79:214-221.

2. Upadhay MP. Karmacharya PCD, Koirala S, Tuladhar NR.Bryan LL Smolin D et al. Epidemiologic characteristics, predisposing factors and etiological diagnosis of corneal ulceration in Nepal. Am J Ophthalmo/1988; 106:92-99.

3. Polack MXaufinan HE. Newmark E. Keratomycosis. Medical and surgical management. AIt:h Ohthalmo/1981; 85:410-16.

4. Mino de Kaspar H. ZOlllek G. Pm'des ME. Albomo R. Medina D, Centurion de Moringio $\mathrm{M}$ el al. Mycotic keratitis in Paraguay. Mycoses 1991; 34:251-54.

5. Sharma S, Srinivasan M, George C: The current status of Fusarium species in mycotic keratitis in South India. J Med Microbiol 1993, 11:140-147.
Despite the low level of Keratomycosis in this study, high index of suspicion of possible diagnosis should be given to patients with history of trauma, tissue devitalization with topical steroids and immunocompromised immunity. Corneal scrapings of the patients should be sent to the laboratory as early as possible for prompt diagnosis.

\section{Recommendations}

Nigeria is the most populous black African nation .The increased incidence of fungal keratitis warrants further study of the risk factors, antifungal susceptibility testing, and possible pharmacologic combinations to prevent blindness. Research toward rapid diagnosis and specific drug therapy that could minimize the morbidity caused by this preventable disease will be appreciated in University College Hospital, Nigeria.

\section{ACKNOWLEDGEMENTS}

The Authors wish to thank the Consultant Ophthalmologists, Clinical Microbiologists, Residents Doctors in the two departments (Medical Microbiology and Ophthalmology), Laboratory Scientists ,Public Health nurses ( U.C.H. , Ibadan, Nigeria.) and the study patients for their assistance during the period of study.

6. Upadhyay MP, Karmacharya PC, Koirala S, et al. Epidemiologic characteristics, predisposing factors, and etiologic diagnosis of corneal ulceration in Nepal. Am J Ophthalmol 1991, 15:92-99.

7. Dunlop AA, Wright ED, Howlader SA, et al.: Suppurative corneal ulceration in Bangladesh: a study of 142 cases examining the microbiological diagnosis, clinical and epidemiological features of bacterial and fungal keratitis. Aust N Z J Ophthalmol 1994, 22:105-110.

8. Leck AK, Thomas PA, Hagan M, et al.: Aetiology of suppurative corneal ulcers in Ghana and South India, and epidemiology of fungal keratitis. Br J Ophthalmology 2002, 86:1211-1215.

9. Hagan M, Wright E, Newman M, et al.: Causes of suppurative keratitis in Ghana. Br J Ophthalmol 1995, 79:1024-1028. 
10. Liesegang TJ, Forster RK: Spectrum of microbial keratitis in South Florida. Am J Ophthalmol 1980, 90:38-47.

11. Gopinathan U, Garg P, Fernandez M, et al.: The epidemiological features and laboratory results of fungal keratitis: a 10-year review at a referral eye care center in South India. Cornea 2002, 21:555-559.

12. Chander J, Sharma A. Prevalence of fungal corneal ulcers in Northern India Jnjeclion.1994: 22:207-09.

13. Venugopal PL. Venugopal TL. Gomathi A, Ramakrishnan S. liavarasi S Mycotic keratitis in Madras. Ind J Pathol M BioI 1989: 32: 19097.

14. Srinivasan, M, Fungal keratitis. Curr Opin Ophthalmol 2004: 15:321-327.

15. Prajna NV, Rao RA, Mathen MM, Prajna L, George C, Srinivasan M. Simultaneous bilateral Fungal Keratitis caused by different fungi. Indian J Opthalmol 2002;50:213-214

16. Deshapande SD, Koppikar GV. A study of Mycotic keratitis in Mumbai. Indian J Pathol Microbial 1999;42(1):81-87.
17. Kotigadde S, Ballal M, Jyothirlatha, Kumar A, Rao SRN, Shivananda PG. Mycotic keratitis: A study in costal Karnataka. Indian J Ophthalmol 1992;40(1):31-33

18. Thomas PA: Current perspectives on ophthalmic mycoses. Clin Microbiol Rev; 2003, 16:730-797.

19. Chang CW, Ho CK, Chen ZC, et al.: Fungi genus and concentration in the air of onion fields and their opportunistic action related to mycotic keratitis. Arch Environ Health 2002, 57:349-354.

20. Gopinathan U, Garg P, Fernandes M, et al.: The epidemiological features and laboratory results of fungal keratitis: a 10-year review at a referral eye care center in South India. Cornea 2002, 21:555-559.

21. Tanure MA, Cohen EJ, Sudesh S, et al.: Spectrum of fungal keratitis at Wills Eye Hospital, Philadelphia, Pennsylvania. Cornea 2000, 19:307-312. 